\title{
Prevalence of geriatric depression in the Kavre district, Nepal: Findings from a cross sectional community survey
}

Kedar Manandhar ${ }^{1,2}$, Ajay Risal ${ }^{1,3^{*}}$ (D), Oshin Shrestha', Nirmala Manandhar ${ }^{4}$, Dipak Kunwar ${ }^{1,3}$, Rajendra Koju ${ }^{1,5}$ and Are Holen ${ }^{6}$

\begin{abstract}
Background: The increasing elderly population worldwide is likely to increase mental health problems such as geriatric depression, which has mostly been studied in high-income countries. Similar studies are scarce in low-andmiddle-income-countries like Nepal.

Methods: A cross-sectional, population-based, door-to-door survey was conducted in randomly selected rural and urban population clusters of the Kavre district, Nepal. Trained nurses (field interviewers) administered structured questionnaires that included a validated Nepali version of the Geriatric Depression Scale short form (GDS-15) for identifying geriatric depression among the elderly ( $\geq 60$ years) participants $(N=460)$. Those scoring $\geq 6$ on GDS-15 were considered depressed. Logistic regression analysis explored the associations of geriatric depression with regard to socio-demographic information, life style, family support and physical well-being.

Results: Of the total 460 selected elderly participants, 439 (95.4\%) took part in the study. More than half of them were females (54.2\%). The mean age was $70.9( \pm 8.6)$ years. Approximately half $(50.6 \%)$ were rural inhabitants, the majority (86.1\%) were illiterate, and about three-fifths (60.1\%) were living with their spouses. The gender-and-age adjusted prevalence of geriatric depression was $53.1 \%$. Geriatric depression was significantly associated with rural habitation (AOR 1.6), illiteracy (AOR 2.1), limited time provided by families (AOR 1.8), and exposure to verbal and/or physical abuse (AOR 2.6).
\end{abstract}

Conclusion: Geriatric depression is highly prevalent in Kavre, Nepal. The findings call for urgent prioritization of delivery of elderly mental health care services in the country.

Keywords: Depression, Elderly, Lifestyle, Mental health, Prevalence

\section{Background}

Worldwide, the elderly population is rapidly growing. The number of the elderly aged 60 years and above is projected to double by 2050; the biggest increments will be found in the low-and middle-income (LAMI) countries [1]. These demographic changes are expected to create substantial challenges for the social and health care services with a major increase in chronic diseases,

\footnotetext{
* Correspondence: drajayrisal@gmail.com

'Dhulikhel Hospital, Kathmandu University Hospital, Dhulikhel, Kavre, Nepal

${ }^{3}$ Department of Psychiatry, Kathmandu University School of Medical

Sciences, GPO Box 11008, Dhulikhel, Kavre, Nepal

Full list of author information is available at the end of the article
}

physical disabilities, and mental health problems such as depression $[1,2]$.

Geriatric depression is an important public health concern that impairs the quality of life (QoL) and imposes financial costs on the family and society [3-8]. The Global Burden of Disease Study 2017 (GBD 2017) ranked depression as the third most leading cause of the years of life lost to disability (YLD) [9]. Most studies on geriatric depression have been carried out in high-income countries [2, 10,11]; similar studies are relatively few in the LAMI countries [11] such as Nepal.

Nepal is one of the resource-poor countries within the South-East Asia Region (SEAR). About one quarter of the total population live below the international poverty

(c) The Author(s). 2019 Open Access This article is distributed under the terms of the Creative Commons Attribution 4.0 International License (http://creativecommons.org/licenses/by/4.0/), which permits unrestricted use, distribution, and reproduction in any medium, provided you give appropriate credit to the original author(s) and the source, provide a link to the Creative Commons license, and indicate if changes were made. The Creative Commons Public Domain Dedication waiver (http://creativecommons.org/publicdomain/zero/1.0/) applies to the data made available in this article, unless otherwise stated. 
line [12]. The population is approximately 30 millions; around one tenth is 60 years and above [13-15]. Though the percentage of the elderly in Nepal is not as high as in the high-income countries, there is, nevertheless, an increasing proportion of the elderly in the population, partly due to declining infant mortality and the crude birth rate [14].

The prevalence of elderly depression is expected to be high in Nepal, as per the results from other available studies [16-22]. However, most of the existing local studies have been conducted in geriatric homes [16-18, 21], or in clinical settings [19]. Very few studies are performed in community settings [20, 22, 23], and those have mostly been carried out in Kathmandu, the capital of Nepal [20, 22]. The prior findings are thus not likely to be representative of the entire geriatric population of the country with its vast socio-cultural and ethnic diversity.

Accordingly, we conducted a study of a community based sample, accommodating both the rural and urban populations. The Kavre district was a rather suitable candidate in this regard. The primary objective of the study was to estimate the prevalence of depression among the elderly in the Kavre district. The secondary objective was to identify factors associated with geriatric depression such as demographic, life-style, family related support and physical well-being. The purpose was to inform the health policy makers about the needs, and to provide foundations for better health-care resource allocations in the country.

\section{Methods}

\section{Ethics}

The Institutional Review Committee of Kathmandu University School of Medical Sciences (IRCKUSMS), Dhulikhel Hospital, Kavre, Nepal approved the study protocol.

All invited participants were informed about the nature, purpose and procedures of study. They were also informed that they were free to withdraw their consent and discontinue the research interviews at any time. In addition, they had the opportunity to ask any questions they would like regarding the study. Before the interviews began, written consent was given by those participants who could read and write, while fingerprints were collected from those who were unable to do that.

\section{Study design and sampling}

Data collection was made in January and February 2019. The design was a cross-sectional, population-based, doorto-door survey based on field interviews conducted in the Kavre district, which falls under Province no 3, Nepal. It comprises seven rural and six urban municipalities. According to the Central Bureau of Statistics (CBS) 2011 [15], the total population was 381,937 (males 182,936 [47.9\%] and females 199,001 [52.10\%]. In this population,
36,912 were elderly aged 60 years or above (9.6\% [males 9.7\% and females 9.6\%]).

\section{Inclusion and exclusion criteria}

The inclusion criteria for age was 60 years and above. The participants should live in the Kavre district and be able to speak Nepali. Moreover, elderly persons who had lost the ability to speak or had major hearing loss, who were disoriented were excluded, i.e., they were unable to give correct answers to at least two of the three following questions (i) time of day [morning, day and evening], (ii) location [outside or inside the house], and (iii) weekday of the data collection [Sunday to Saturday], and those who were residing in old-age homes.

\section{Sample size and sampling procedures}

We estimated a sample size of 460 persons by using the formula $\mathrm{Z}^{2} \mathrm{pq} / \mathrm{d}^{2}$ assuming a prevalence of depression (p) $60.0 \%$, a precision (d) $5.0 \%$ of p with $95 \%$ confidence interval (CI), and adding a $20 \%$ non-response rate.

We used a multistage systematic random sampling procedure to recruit eligible participants. In the first stage, four municipalities, two out of six urban and two out of seven rural municipalities of the Kavre district were selected by using a lottery method. We allocated equal proportions of participants (115 elderly) for each municipality to ensure a balanced representation from rural and urban areas. In the second stage, we selected at least $50 \%$ of the wards (administrative units) from each selected municipality also by using the lottery method.

The field interviewers sketched the ward map. They listed and numbered households with elderly inhabitants. This was achieved by help from the Female Community Health Volunteers (FCHVs); they are local women working voluntarily to enrich the outreach health care services at the community level. From the list, we selected households using a systematic random sampling technique. In the third stage, we selected one elderly person from each household. If there were two or more elderly in the household, one of them was selected randomly using the lottery method.

\section{Participants}

Of the potential 460 selected elderly individuals, 13 declined to participate, six had impaired hearing, and two were unavailable. These 21 elderly (10 male, 11 female; age 60-85 years [ 13 urban and 8 rural]) were regarded as non-participants. Finally, 439 persons participated in the study. Thus, the proportion of participation was $95.4 \%$.

A comparison of representativity has been made in Table 1 between the age and gender distribution of our selected samples of the elderly and the figures from the CBS [15]. The selected sample proved to be quite representative of the elderly population of the Kavre district, 
Table 1 Age and gender distribution of elderly in a randomly selected sample $(N=439)$ from the Kavre district, Nepal compared with national figures ${ }^{a}$

\begin{tabular}{|c|c|c|c|c|c|c|}
\hline \multirow{3}{*}{$\begin{array}{l}\text { Age } \\
\text { (in } \\
\text { years) }\end{array}$} & \multicolumn{2}{|l|}{ All } & \multicolumn{2}{|l|}{ Male } & \multicolumn{2}{|l|}{ Female } \\
\hline & $\overline{\text { Kavre }^{a}}$ & Sample & $\overline{\text { Kavre }^{a}}$ & Sample & Kavre $^{a}$ & Sample \\
\hline & $n(\%)$ & $n(\%)$ & $n(\%)$ & $n(\%)$ & $n(\%)$ & $n(\%)$ \\
\hline $60-64$ & $11,437(30.9)$ & $124(28.2)$ & 5425 (30.6) & $56(27.9)$ & 6012 (28.6) & $\begin{array}{l}68 \\
(28.6)\end{array}$ \\
\hline 65-69 & 9336 (25.3) & 77 (17.5) & 4529 (25.6) & 35 (17.4) & 4807 (25.0) & $\begin{array}{l}42 \\
(17.6)\end{array}$ \\
\hline 70-74 & 6937 (18.8) & $105(24.0)$ & 3355 (19.0) & $45(22.4)$ & 3582 (18.6) & $\begin{array}{l}60 \\
(25.2)\end{array}$ \\
\hline$\geq 75$ & $9202(25.0)$ & $133(30.3)$ & 4386 (24.8) & $65(32.3)$ & $4816(25.1)$ & $\begin{array}{l}68 \\
(28.6)\end{array}$ \\
\hline Total & $36,912(100.0)$ & $439(100.0)$ & $17,695(47.9)$ & $201(45.8)$ & $19,217(52.1)$ & $238(54.2)$ \\
\hline
\end{tabular}

${ }^{\mathrm{a}}$ National Population and Housing Census 2011 [15]

despite a rather modest overrepresentation of females and persons of age 70 years and above.

\section{Study instruments}

Face-to-face interviews were done by trained nurses (field interviewers) using a structured questionnaire. The questionnaire was developed in English and translated into Nepali and tested in the field before initiating the data collection (Additional file 1). The final structured interview consisted of six parts (i) personal and demographic characteristics (age, gender, habitation, educational and marital status); (ii) life style related questions (alcohol consumption); (iii) family support (time provided by family, financial support, perceived respect from family, and verbal and/or physical abuse by family); (iv) questions that map the elderly person's physical condition with regard to chronic physical health problems; the subjective report of any of the following diseases: diabetes, chronic obstructive pulmonary diseases [COPD], heart disease, cancer, paralyses and/or mobility problems; (v) questions from the Geriatric Depression Scale short form (GDS-15) [24]. A detailed description of the scale is given below. The last part (vi) consisted of biometric measurements such as height, weight, waist circumference and blood pressure (BP).

\section{Geriatric depression scale short form (GDS-15) - Nepali version}

We used the Geriatric Depression Scale short form (GDS-15) to scan the potential presence of depressive symptoms [24]. The instrument had already been used in Nepal [22, 23] and in other Asian countries [25-27] including India [28] and Pakistan [29].

The original English version GDS-15 [24] was translated into Nepali. For the validation, the Nepali version was administered to the total of 106 participants from the Kavre district (mean age 68.1) by trained nurses. The participants were later blindly interviewed by the local consultant psychiatrists for possible geriatric depression according to the criteria of the International Classification of Diseases-10 (ICD-10).

In the validation study, 5/6 was found to be the optimal cut-off point also in Nepal. The internal consistency was found to be 0.79 , and the sensitivity (Se) was $86.3 \%$ and the specificity (Sp) was $74.5 \%$. Further details of the validation study will be published elsewhere (Risal et al.).

The GDS-15 consists of 15 items; they are focusing on the psychological symptoms that the person felt during the past week. Each item is rated in a yes/no format. Among them, 10 items (2, 3, 4, 6, 8. 9, 10, 12, 14 \& 15) indicate the presence of depression when answered "yes" (positive), while the remaining 5 items $(1,5,7,11$ \& 13) indicated depression when answered "no" (negative). The potential total score ranged from 0 to 15 [24].

\section{Assessment of geriatric depression}

A score of 5 or less was considered to be within the normal range and classified as a "no case" of geriatric depression, while 6 or more endorsements were considered to indicate a caseness of geriatric depression according to the validation study.

\section{Statistical analysis}

We estimated the crude prevalence of geriatric depression with a $95 \%$ confidence interval (CI), and we adjusted the prevalence for gender and age according to the population distribution of the elderly aged $\geq 60$ years of the Kavre district, as found in the data from the CBS [15].

The depression status of the GDS-15 was used as the dependent variable and the responses were dichotomized into yes (case of geriatric depression) or no (no case of geriatric depression).

Moreover, we dichotomized the socio-demographic variables like age ( $<75$ or $\geq 75$ years), gender (male or female), habitation (urban or rural), educational status (literate or illiterate), and marital status (married or unmarried/ 
widowhood/separate); life style factors including alcohol consumption (yes or no); family support in terms of the time provided by the family (yes or no), source of financial support (her/himself or family), perceived respect from family (yes or no), and verbal and/or physical abuse (no or yes); and any physical condition that included limited mobility ('able to go out of home' or 'not able to go out of home'); and finally, any chronic physical health problem (yes or no).

Bivariate and multivariate logistic regression analyses with odds ratios [ORs] and adjusted ORs [AORs] respectively were used, each with $95 \%$ CIs to investigate the associations of geriatric depression with the above mentioned variables.

The $p$-values $<0.05$ were considered statistically significant.

The statistical analyses were carried out using the Statistical Package for Social Science software (IBM SPSS Statistics 21, Chicago, USA).

\section{Results}

\section{Socio-demographic characteristics}

The socio-demographic characteristics of the participants have been presented in the Table 2. Of the 439 participants, $201(45.8 \%)$ were males and the rest 238 (54.2\%) were females. The mean age was 70.9 (SD 8.6) years. A large majority (86.1\%) were illiterate, and about three-fifths $(60.1 \%)$ were married and living with their spouse.

\section{Prevalence}

The crude prevalence of geriatric depression was $56.0 \%$ (95\% CI 51.3-60.7). The gender-and-age adjusted prevalence was $53.1 \%$ and the age-adjusted female-to-male ratio was 1.14 .

The prevalence of geriatric depression was found to be higher among females than among males (59.2\% vs. $52.2 \%)$, more prevalent among those above 75 years $(66.9 \%$ vs. $51.3 \%$ ) and also, among those from rural areas compared to those from urban areas (63.5\% vs. $48.4 \%)$. In addition, geriatric depression was more prevalent among the illiterate $(59.8 \%$ vs. $32.8 \%)$ and among those who were unmarried, widowed or divorced (63.3\% vs. $49.2 \%)$ (Table 3 ).

\section{Socio-demographic associations}

The associations between geriatric depression and the socio-demographic variables have been presented in Table 4.

In the bivariate analyses, the geriatric depression was more frequent in the older age group ( $\geq 75$ years) (OR 1.9 [95\% CI1.3-2.9]; $p=0.003)$, among those residing in the rural areas (OR 1.9 [95\% CI 1.3-2.7]; $p=0.001$ ), among those who were illiterate (OR 3.1 [95\% CI 1.7-5.1]; $p<$ 0.001 ), and among those being unmarried/widowhood/ divorced (OR 2.0 [95\% CI 1.4-3.0]; $p<0.001$ ).
Table 2 Socio-demographic characteristics of a randomly drawn sample of the elderly $(n=439)$

\begin{tabular}{lll}
\hline Variables & N & $\%$ \\
\hline Age (in years) & 306 & 69.7 \\
$<75$ & 133 & 30.3 \\
$\geq 75$ & & \\
Gender & 201 & 45.8 \\
Male & 238 & 54.2 \\
Female & & \\
Residence & 217 & 49.4 \\
Urban & 222 & 50.6 \\
$\quad$ Rural & & \\
Educational status & 61 & 13.9 \\
Literate & 378 & 86.1 \\
Illiterate & & 60.1 \\
Marital status & 264 & 39.9 \\
Married & 175 & \\
$\quad$ Unmarried/widowed/divorce & & 73.1 \\
Current smoker & 321 & 26.9 \\
No & 118 & \\
Yes & & \\
Current alcohol consumer & 331 & \\
No & 108 & \\
\hline
\end{tabular}

Table 3 Prevalence of geriatric depression by sociodemographic characteristics of elderly $(n=439)$

\begin{tabular}{|c|c|c|c|}
\hline Variables & $\mathrm{n}$ & $\begin{array}{l}\text { Prevalence } \\
\mathrm{n}(\%)\end{array}$ & $95 \% \mathrm{Cl}$ \\
\hline \multicolumn{4}{|l|}{ Age (in years) } \\
\hline$<75$ & 306 & $157(51.3)$ & $45.6-57.0$ \\
\hline$\geq 75$ & 133 & $89(66.9)$ & $58.2-74.8$ \\
\hline \multicolumn{4}{|l|}{ Gender } \\
\hline Male & 201 & $105(52.2)$ & $45.1-59.3$ \\
\hline Female & 238 & $141(59.2)$ & $52.7-65.5$ \\
\hline \multicolumn{4}{|l|}{ Residence } \\
\hline Urban & 217 & $105(48.4)$ & $41.6-55.2$ \\
\hline Rural & 222 & $141(63.5)$ & $56.8-69.9$ \\
\hline \multicolumn{4}{|l|}{ Educational status } \\
\hline Literate & 61 & $20(32.8)$ & $21.3-46.0$ \\
\hline Illiterate & 378 & $226(59.8)$ & $54.7-64.8$ \\
\hline \multicolumn{4}{|l|}{ Marital status } \\
\hline Married & 264 & $130(49.2)$ & $43.1-55.4$ \\
\hline Unmarried/widowed/divorce & 175 & $116(63.3)$ & $58.8-73.2$ \\
\hline
\end{tabular}

Cl confidence interval 
Table 4 Bivariate and multivariate logistic regression analyses of associations of geriatric depression with dichotomized variables of socio-demographic information, life style, family support and physical well-being among the elderly $(n=439)$

\begin{tabular}{|c|c|c|c|c|c|}
\hline \multirow[t]{2}{*}{ Variables } & \multirow[t]{2}{*}{$n(\%)$} & \multicolumn{2}{|c|}{ Bivariate analyses } & \multicolumn{2}{|c|}{ Multivariate analyses } \\
\hline & & $\mathrm{OR}(95 \% \mathrm{Cl})$ & $p$ & $\overline{\operatorname{AOR}^{a}(95 \% C l)}$ & $p$ \\
\hline \multicolumn{6}{|l|}{ Socio-demographic variables } \\
\hline \multicolumn{6}{|l|}{ Age (in year) } \\
\hline$<75$ & $306(69.7)$ & reference & - & reference & - \\
\hline$\geq 75$ & $133(30.3)$ & $1.9(1.3-2.9)$ & 0.003 & $1.3(0.8-2.1)$ & 0.36 \\
\hline \multicolumn{6}{|l|}{ Gender } \\
\hline Male & $201(45.8)$ & reference & - & reference & - \\
\hline Female & $238(55.2)$ & $1.3(0.9-1.9)$ & 0.14 & $0.9(0.5-1.4)$ & 0.53 \\
\hline \multicolumn{6}{|l|}{ Residence } \\
\hline Urban & $217(49.4)$ & reference & - & reference & - \\
\hline Rural & $222(50.6)$ & $1.9(1.3-2.7)$ & 0.001 & $1.6(1.1-2.4)$ & 0.046 \\
\hline \multicolumn{6}{|l|}{ Educational status } \\
\hline Literate & $61(13.9)$ & reference & - & reference & - \\
\hline Illiterate & $378(86.1)$ & $3.1(1.7-5.1)$ & $<0.001$ & $2.1(1.1-4.0)$ & 0.037 \\
\hline \multicolumn{6}{|l|}{ Marital status } \\
\hline Married & $265(60.1)$ & reference & - & reference & - \\
\hline Unmarried/widowhood/separate & $175(39.1)$ & $2.0(1.4-3.0)$ & $<0.001$ & $1.4(0.9-2.4)$ & 0.16 \\
\hline \multicolumn{6}{|l|}{ Current alcohol consumption } \\
\hline No & $331(75.4)$ & reference & - & reference & - \\
\hline Yes & $108(24.6)$ & $1.5(0.9-2.4)$ & 0.059 & $1.6(0.9-2.7)$ & 0.065 \\
\hline \multicolumn{6}{|l|}{ Family support variables } \\
\hline \multicolumn{6}{|l|}{ Time given by family } \\
\hline Yes & $274(62.4)$ & reference & - & reference & - \\
\hline No & 165 (37.6) & $3.0(2.0-4.5)$ & $<0.001$ & $1.8(1.1-2.9)$ & 0.012 \\
\hline \multicolumn{6}{|l|}{ Financial support } \\
\hline Self-manage & $277(63.1)$ & reference & - & reference & - \\
\hline Family support & $162(36.9)$ & $0.8(0.5-1.3)$ & 0.18 & $0.8(0.5-1.2)$ & 0.38 \\
\hline \multicolumn{6}{|l|}{ Perceived respect from family } \\
\hline Yes & $389(88.6)$ & reference & - & reference & - \\
\hline No & $50(11.4)$ & $4.1(1.9-8.7)$ & $<0.001$ & $2.1(0.9-4.9)$ & 0.069 \\
\hline \multicolumn{6}{|l|}{ Verbal and/or physical abuse by family } \\
\hline No & $348(79.3)$ & reference & - & reference & - \\
\hline Yes & $91(20.7)$ & $3.8(2.2-6.6)$ & $<0.001$ & $2.6(1.4-4.8)$ & 0.002 \\
\hline \multicolumn{6}{|l|}{ Physical well-being } \\
\hline \multicolumn{6}{|l|}{ Chronic physical health problems } \\
\hline No & $281(64.0)$ & reference & - & reference & - \\
\hline Yes & $158(36.0)$ & $1.7(1.1-2.5)$ & 0.013 & $1.8(1.2-2.8)$ & 0.012 \\
\hline \multicolumn{6}{|l|}{ Mobility (ability to go out of home) } \\
\hline Able to go out of home & $291(66.3)$ & reference & - & reference & - \\
\hline Unable to go out of home & $148(33.7)$ & $2.3(1.5-3.4)$ & $<0.001$ & $1.4(0.9-2.3)$ & 0.046 \\
\hline
\end{tabular}

adjusted age, gender, residence, education status, marital status, current alcohol consumption, time given by family, financial support, perceived respect from family, verbal and/or physical abuse by family, physical mobility and presence of physical chronic health problem; AOR Adjusted odds ratio, $C l$ confidence interval 
In the multivariate analyses, however, only two characteristics showed statistical significance; they were residency in the rural areas (AOR 1.6 [95\% CI 1.1-2.4]; $p=$ 0.046), and being illiterate (AOR 2.1 [95\% CI 1.1-4.0]; $p=0.037)$.

\section{Life style, family support and physical conditions}

The associations between geriatric depression and life style, family support and physical well-being variables have been presented in Table 4 .

In the bivariate analyses, the elderly who reported not to be given enough time by their families (OR 3.0 (2.0-4.5); $p<0.001$ ), and those who perceived that they received no respect (OR 4.1 [95\% CI 1.9-8.7]; $p<0.001$ ), and those experiencing verbal and/or physical abuse by their family (OR 3.8 [95\% CI 2.2-6.6]; $p<0.001$ ) were found to have geriatric depression more frequently.

However, only those elderly who were not given enough time by their families (AOR 1.8 [95\% CI 1.1-2.9]; $p=$ 0.012 ) and those who reported verbal and/or physical abuse by their families (AOR 2.6 [95\% CI 1.4-4.8]; $p=$ 0.002 ) came out as statistically significant in the multivariate analyses.

Both the bivariate and multivariate analyses showed statistically significant associations between geriatric depression and the presence of any of the chronic physical health problems, and also, between geriatric depression and the inability to move out of the home (limited mobility).

\section{Discussion}

To our knowledge, this is the first community-based door-to-door survey that estimates the prevalence and explores the associations of depression in the elderly population in Nepal. The Kavre district is fairly representative of Nepal as a whole. Depression was assessed using the GDS-15, a validated inventory in Nepali with the cut-off point at scores 5/6.

We found more than half of the elderly population in the Kavre district to suffer from some degree of depression; age and gender standardized prevalence was 53.1\%. The risk of having geriatric depression was found to be higher among those residing in the rural areas, and among those who were illiterate. The odds of having a geriatric depression were also higher among those who reported not to be given enough time by their families and among those who reported verbal and/or physical abuse by their families. Furthermore, geriatric depression was more likely to be present among those elderly who had limited mobility and among those who suffered from any of the chronic physical illnesses typical of the elderly.

The prevalence of geriatric depression was slightly lower than what has been found in earlier community-based studies in Nepal $[22,23]$. In the past studies, another cut- off point [4/5] was used for the same screening instrument [GDS-15]. The most noticeable finding is that the prevalence of geriatric depression in our study is considerably higher than what has been found in population-based studies from various other Asian countries; $45 \%$ in Bangladesh [30]; 30.8\% in China [31], 33.8\% in Indonesia [32], 33.3\% in Japan [33], 39.7\% in Korea [34], 48.3\% in Laos [35], 22.9\% in Myanmar [36], 40.6\% in Pakistan [29], 27.8\% in Sri Lanka [37], 22.2\% in Singapore [38], 27.5\% in Taiwan [39], 27.5\% in Thailand [40], and $17.2 \%$ in Vietnam [33]. It is noteworthy that depression among adults (18-65 years) in a recently conducted nationwide study population in Nepal was also found to be higher than the global mean [41].

In our view, cross-country comparisons should be interpreted with some caution due to methodological differences [11], differences in the instruments and differences in the cut-off points. There are also differences in the age ranges and the socio-cultural settings in which the studies were conducted.

We noticed that most of the studies were carried out in countries relatively more developed than Nepal. Nepal is the country where the primary health care delivery system is largely under-resourced; there is still a lack of trained personnel related to mental health in the primary care settings [42]. In the LAMI countries in general, the majority of the cases of mental illness are untreated because of shortage of mental health professionals [43]. In Nepal, that could be one of the most relevant factors for explaining the higher prevalence of geriatric depression.

We find it most fruitful to compare our findings with Asian studies using the same scale (GDS-15) and the same cut-off point (5/6), and in fairly similar community settings. Even so, the prevalence in Nepal appears to be higher than elsewhere. A similar prevalence figure (48.3\%) of geriatric depression, using the same screening instrument at the same cut-off point, was found in Laos [35], a country with economic conditions comparable to those of Nepal.

Socio-cultural factors may affect mental health problems in the underdeveloped societies. Health care practices are largely related to the social norms and values among the community members [11]. In countries like Nepal, there is still a widespread belief that disclosure of mental illness is an embarrassment and may lead to discrimination [41]. The stigma associated with mental illness may contribute towards underreporting as opposed to physical symptoms [44]. Using the same cut-off (5/6) of GDS-15, an almost similar prevalence of geriatric depression (47.0\%) was reported from India [28], a country with more or less similar socio-cultural attributes as Nepal.

The literature is conflicting with regard to the age and gender associations of geriatric depression [22, 23, 29, 37]. Though the prevalence among females was higher than for the males, the difference was not found to be statistically 
significant. The higher prevalence among those above 75 years seen in the bivariate analyses did not survive the multivariate analysis.

In line with other studies [22, 37], we found higher prevalence of depression among the illiterate elderly. Probably illiteracy limits the opportunities to engage in better works or employment. Therefore, those who are elderly and illiterate are more likely to be lower in socio-economic status and financially more insecure [37] in the later stages of life. This may lead to prolonged stress, negative perception of social support, and a lack of control over their social environment. Together, these factors may contribute towards depression [45].

There is a limited literature exploring the associations between geriatric depression and residence in rural areas. In contrast to the findings in Sri Lanka [37], we found the prevalence of geriatric depression to be higher among the elderly residing in the rural areas. The probable explanation could be due to the high level of migration in Nepal of the younger bracket of the population to urban or other countries for employment. Ultimately, the lonely elderly are likely to be home with fewer persons to care for them.

Absence of family support is strongly associated with geriatric depression with a probable bidirectional interaction $[46,47]$. The reduced presence of close family members or low social interactions are both recognized as important predictors of depression among the elderly [11, 47, 48]. Consistent with a previous study [22], our study revealed that those elderly who were not given enough time and those reporting physical and/or verbal abuse by their family were more prone to having geriatric depression. The elderly in Nepal rarely live alone, and they rather want to live with their family and there seek love, affection, care and protection. Due to the rapid urbanization and acculturation in the country, the extended family system has been subject to changes from the joint to the nuclear family. The traditional values towards the elderly have also partly been erased; the elderly are more often left alone, neglected, abused and regarded as a burden to the family in contemporary Nepal [49].

The higher odds of having geriatric depression among the participants with one or more chronic physical disease and/or the inability to go out of their homes due to poor mobility have consistently been reported in many studies [22, 50, 51]. Though the relations between chronic physical health problems and geriatric depression could be bidirectional, we believe that long standing physical health problems among the elderly not only imposes a financial burden but also causes functional limitations related to mobility, physical activity in the dayto-day activities. This is likely to undermine the social life of the elderly. Moreover, poor mobility makes the elderly more dependent on others' presence and involves a loss of autonomy. These problems and implications may negatively affect the psychological well-being of the elderly, and in some cases, this may ultimately result in geriatric depression.

\section{Strengths and limitations}

The very high participation rate $(95.4 \%)$ within the randomly drawn sample, involving random selection of the rural and urban clusters reduced the chances of participation bias. The careful face-to-face interviews ensured hardly any missing data. Support of the FCHVs during the household survey ensured acceptance in the community. The selected sample was found to be more or less representative of the population of Kavre district, which again is fairly representative of the nation as a whole. We used a standardized and validated instrument for $\mathrm{Nepal}$; it had been used and validated in many other Asian countries, but so far, not in Nepal before this study. These are some strengths of the study.

Of limitations, we want to point out that this is a cross sectional study. We cannot establish causal relationships. The presence of chronic physical health problems was based on self-reports and over- or underreporting may have happened. To minimize this source of error, the trained nurses who served as field interviewers in the data collection, also cross-checked the medical reports or medication in the homes, if any. Using many dichotomous variables for studying the associations may have compromised some of our findings. Due to resource limitations, we were unable to use structured interviews to establish the psychiatric diagnosis of the participants.

\section{Conclusions}

Geriatric depression is highly prevalent in Kavre, Nepal. This mental health condition is associated with sociodemographic factors such as residing in rural areas and illiteracy, low family support in terms of little time given to the elderly and/or exposure to physical and/or verbal abuse, but also the absence of physical well-being. Some of the depressed elderly were unable to go out of their homes, and some suffered from at least one chronic physical health condition. From a public health perspective, there are urgent needs for clearer health-care priorities for the elderly in Nepal. The findings of this study may be used to inform anyone connected to the health care system in the country, and in particular the policy makers for the development of relevant public health and social programs for the prevention and control of depression among the elderly.

\section{Additional file}

Additional file 1: English version of the questionnaire. English version of the questionnaire administered by the field interviewers to the study participants. (PDF $213 \mathrm{~kb}$ ) 


\section{Abbreviations}

AOR: Adjusted odds ratio; BP: Blood pressure; CBS: Central Bureau of Statistics; Cl: Confidence interval; COPD: Chronic obstructive pulmonary diseases; FCHV: Female community health volunteer; GBD : The Global Burden of Disease; GDS: Geriatric Depression Scale; ICD: International Classification of Disease; IRCKUSMS: Institutional Review Committee of Kathmandu University School of Medical Sciences; LAMI: Low-and middleincome; OPD: Out patients department; OR: Odds ratio; QoL: Quality of life; SD: Standard deviation; Se: Sensitivity; SEAR: South-East Asia Region; Sp: Specificity; UGC: University Grants Commission; YLD: Years of life lost to disability

\section{Acknowledgments}

We would like to honor Late Kedar Manandhar (the first author) for his major contribution to this paper. He is no more with us; he left this world before the completion of this paper.

We also would like to thank the University Grants Commission (UGC), Nepal, for the academic research grant, and Dhulikhel Hospital, Kathmandu University School of Medical Sciences, Dhulikhel, Kavre, Nepal, for the technical support.

\section{Authors' contributions}

$K M, A R$, and NM, with the support from $A H$ and RK were involved in the conception and design of the study. OS, AR, KM, DK and NM were responsible for the data acquisition. $A R$ and $K M$ were engaged in the data analysis and interpretation. KM drafted the initial manuscript; AR was later involved in the necessary modifications and completion of the manuscript for publication. All authors revised the manuscript critically for intellectual content and approved the submitted version.

\section{Funding}

This academic research project was funded by the University Grants Commission (UGC), Nepal (Faculty Research Grant; awarded No FRG-74/75HS-15; Date 27 Sept, 2018). The funding body was not involved in the design of the study, in the collection, analysis, and interpretation of the data, or in the writing of the manuscript.

\section{Availability of data and materials}

Personal identification details of the participants were separated from the completed questionnaires and stored in a locked room at the Kathmandu University School of Medical Sciences (KUSMS). No information related to identifiable individuals was disseminated beyond those researchers immediately involved in the study.

The data sets used and analyzed in this study are available from the corresponding author on reasonable request.

\section{Ethics approval and consent to participate}

The Institutional Review Committee of Kathmandu University School of Medical Sciences (IRCKUSMS), Dhulikhel Hospital, Kavre, Nepal approved the study protocol.

Before the interviews began, written consent was given by all those participants who could read and write, while fingerprints were collected from those who were unable to do so for any reason. The ethics committee (IRCKUSMS) had approved the methods of giving consent.

\section{Consent for publication}

Prior to the interviews, all the prospective participants were given information regarding the study. The participants, who were literate, read the written information approved by the ethics committee; it described the nature and purpose of the study. For those who were illiterate, the field interviewers read the same information in the presence of their family members. Ample opportunity was provided to the participants to discuss the study. The information sheet clearly stated that those who participated in the study also gave their consent to the use of the de-identified information for paper publication.

\section{Competing interests}

None.

\section{Author details}

'Dhulikhel Hospital, Kathmandu University Hospital, Dhulikhel, Kavre, Nepal. ${ }^{2}$ Department of Community Medicine, Kathmandu University School of Medical Sciences, Dhulikhel, Kavre, Nepal. ${ }^{3}$ Department of Psychiatry, Kathmandu University School of Medical Sciences, GPO Box 11008, Dhulikhel, Kavre, Nepal. ${ }^{4}$ Sheer Memorial Hospital College of Nursing, Banepa, Kavre, Nepal. ${ }^{5}$ Department of Medicine, Kathmandu University School of Medical Sciences, Dhulikhel, Kavre, Nepal. ${ }^{6}$ Department of Mental Health, Norwegian University of Science and Technology, Trondheim, Norway.

Received: 8 July 2019 Accepted: 26 August 2019

Published online: 03 September 2019

\section{References}

1. World Health Organization. 10 facts on ageing and health (May, 2017). Retrieved from https://www.who.int/features/factfiles/ageing/en/. Accessed 29 Aug 2019.

2. Ku YL. Integrated Literature Review of Depression in Elderly People. J Gerontol Geriatr Res. 2017;6:446. https://doi.org/10.4172/2167-7182.1000446.

3. Vos T, Barber RM, Bell B, Bertozzi-Villa A, Biryukov S, Bolliger I, Charlson F, Davis A, Degenhardt L, Dicker D, et al. Global, regional, and national incidence, prevalence, and years lived with disability for 301 acute and chronic diseases and injuries in 188 countries, 1990-2013 a systematic analysis for the Global Burden of Disease Study 2013. Lancet (London, England). 2015;386(9995):743-800.

4. Geerlings SW, Beekman AT, Deeg DJ, Twisk JW, Van Tilburg W. The longitudinal effect of depression on functional limitations and disability in older adults an eight-wave prospective community-based study. Psychol Med. 2001;31(8):1361-71.

5. Fassino S, Leombruni P, Abbate Daga G, Brustolin A, Rovera GG, Fabris F Quality of life in dependent older adults living at home. Arch Gerontol Geriatr. 2002;35(1):9-20.

6. Sivertsen $H$, Bjorklof GH, Engedal K, Selbaek G, Helvik AS. Depression and Quality of Life in Older Persons A Review. Dement Geriatr Cogn Disord. 2015:40(5-6):311-39.

7. Unutzer J, Patrick DL, Simon G, Grembowski D, Walker E, Rutter C, Katon W. Depressive symptoms and the cost of health services in $\mathrm{HMO}$ patients aged 65 years and older. A 4-year prospective study. Jama. 1997;277(20):1618-23.

8. Gustavsson A, Svensson M, Jacobi F, Allgulander C, Alonso J, Beghi E, Dodel R, Ekman M, Faravelli C, Fratiglioni L, et al. Cost of disorders of the brain in Europe 2010. Eur Neuropsychopharmacol. 2011;21(10):718-79.

9. James SL, Abate D, Abate KH, Abay SM, Abbafati C, Abbasi N, Abbastabar H, Abd-Allah F, Abdela J, Abdelalim A, et al. Global, regional, and national incidence, prevalence, and years lived with disability for 354 diseases and injuries for 195 countries and territories, 1990-2017 a systematic analysis for the Global Burden of Disease Study 2017. Lancet (London, England). 2018; 392(10159):1789-858.

10. Barua A, Ghosh MK, Kar N, Basilio MA. Worldwide Prevalence of Depression in Elderly. Indian J Gerontol. 2011;25(1):66-75.

11. Djernes JK. Prevalence and predictors of depression in populations of elderly a review. Acta Psychiatr Scand. 2006;113(5):372-87.

12. Central Intelligence Agency. The World Factbook. Retrieved from https:// www.cia.gov/library/publications/the-world-factbook/geos/np.html. Accessed 29 Aug 2019

13. Government of Nepal. National Planning Commission Secretariate, Central Bureau of Statistics Population Monograph of Nepal, Vol I. Kathmandu: Central Bureau of Statistics; 2014

14. Government of Nepal. National Planning Commission Secretariate, Central Bureau of Statistics Population Monograph of Nepal, Vol II. Kathmandu: Central Bureau of Statistics; 2014.

15. Government eof Nepal. National Planning Commission Secretariat, Central Bureau of Statistics National Population and Housing Census 2011, Vol I. In. Central Bureau of Statistics. Kathmandu; 2012

16. Pradhan SN. Depression in elderly. J Psychiattic Assoc Nepal. 2011;1(1):13-4.

17. Ranjan S, Bhattarai A, Dutta M. Prevalence of depression among elderly people living in old age home in the capital city Kathmandu. Health Renaissance. 2013;11(3):213-8.

18. Timalsina R, Sherpa PD, Dhakal DK. Factors Associated with Depression among Elderly Living in Old Age Homes in Kathmandu Valley. J Inst Med. 2014;36(1):90-6 
19. Khattri JB, Nepal MK. Study of depression among geriatric population in Nepal. Nepal Med Col J. 2006;8(4):220-3.

20. Chalise HN, Rai SL. Prevalence and Correlates of Depression among Nepalese Rai Older Adults. Gerontol Res. 2013;2(4):1-5.

21. Chalise HN. Depression among elderly living in Briddashram (old age home). Adv Aging Res. 2014;3(1):6-11.

22. Simkhada R, Wasti SP, GC VS, Lee ACK. Prevalence of depressive symptoms and its associated factors in older adults: a cross-sectional study in Kathmandu, Nepal. Aging \& Mental Health. 2018;22(6):802-7. https://doi. org/10.1080/13607863.2017.1310803.

23. Sharma KR, Yadav BK, Bhattachan M. Correlates of depression among elderly population residing in a community in Eastern Nepal. Birat J Health Sci. 2018;1(5):325-30.

24. Sheikh Jl, Yesavage JA. Geriatric Depression Scale (GDS) Recent evidence and development of a shorter version. Clin Gerontol J Aging Ment Health. 1986;5(1-2):165-73.

25. Imran A, Azidah AK, Asrenee AR. Rosediani M. Prevalence of depression and its associated factors among elderly patients in outpatient clinic of Universiti Sains Malaysia Hospital. Medical J Malaysia. 2009;64(2):134-9.

26. Li J, Theng YL, Foo S. Depression and Psychosocial Risk Factors among Community-Dwelling Older Adults in Singapore. J Cross Cult Gerontol. 2015; 30(4):409-22.

27. Kim Jl, Choe MA, Chae YR. Prevalence and predictors of geriatric depression in community-dwelling elderly. Asian Nurs Res. 2009;3(3):121-9.

28. Reddy NB, Pallavi M, Reddy NN, Reddy CS, Singh RK, Pirabu RA. Psychological Morbidity Status Among the Rural Geriatric Population of Tamil Nadu, India A Cross-sectional Study. Indian J Psychol Med. 2012;34(3):227-31.

29. Bhamani MA, Karim MS, Khan MM. Depression in the elderly in Karachi, Pakistan a cross sectional study. BMC Psychiatry. 2013;13:181.

30. Rahman M, Rahman A, Sajoni TT. Depression Among Rural Aged Facts \& Reasons. AKMMC J. 2015;6(2):20-4.

31. Gao S, Jin Y, Unverzagt FW, Liang C, Hall KS, Ma F, Murrell JR, Cheng Y, Matesan J, Li P, et al. Correlates of depressive symptoms in rural elderly Chinese. Int J Geriatr Psychiatry. 2009;24(12):1358-66.

32. Wada T, Wada C, Ishine M, Okumiya K, Kawakita T, Fushida M, Kita T, Mizuno K, Matsubayashi K. Comprehensive geriatric assessment for communitydwelling elderly in Asia compared with those in Japan $\mathrm{V}$. West Java in Indonesia. Geriatr Gerontol Int. 2005;5:168-75.

33. Wada T, Ishine M, Sakagami T, Kita T, Okumiya K, Mizuno K, Rambo TA, Matsubayashi K. Depression, activities of daily living, and quality of life of community-dwelling elderly in three Asian countries Indonesia, Vietnam, and Japan. Arch Gerontol Geriatr. 2005;41(3):271-80.

34. Lee $Y$, Shinkai S. Correlates of cognitive impairment and depressive symptoms among older adults in Korea and Japan. Int J Geriatr Psychiatry. 2005;20(6):576-86

35. Okumiya K, Ishine M, Wada T, Cruz M, Cruz I, Ishine N, Sakagami T, Kita T, Kaneda E, Moji K, et al. Comprehensive geriatric assessment for communitydwelling elderly in Asia compared with those in Japan IV. Savannakhet in Laos. Geriatr Gerontol Int. 2005;5:159-67.

36. Wada T, Okumiya K, Suzuki K, Roriz-Cruz M, Ishine M, Sakagami T, Kita T, Matsubayashi K. Comprehensive geriatric assessment for communitydwelling elderly in Asia compared with those in Japan VI. Maubin in Myanmar. Geriatr Gerontol Int. 2005;5:276-85.

37. Malhotra R, Chan A, Ostbye T. Prevalence and correlates of clinically significant depressive symptoms among elderly people in Sri Lanka findings from a national survey. Int Psychogeriatr. 2010;22(2):227-36.

38. Matsubayashi K, Ho HK, Okumiya K, Wada T, Ishine M, Wada C, Xin ZG, Kita T, Kato $Y$, Nishihiro N, et al. Comprehensive geriatric assessment for community-dwelling elderly in Asia compared with those in Japan I. Singapore. Geriatr Gerontol Int. 2005;5:99-106.

39. Tsai YF, Yeh SH, Tsai HH. Prevalence and risk factors for depressive symptoms among community-dwelling elders in Taiwan. Int J Geriatr Psychiatry. 2005;20(11):1097-102.

40. Ishine M, Sakagami T, Sakamoto R, Wada T, Khampitak K, Fushida M, Kawakita T, Okumiya K, Kita T, Matsubayashi K. Comprehensive geriatric assessment for community-dwelling elderly in Asia compared with those in Japan VII. Khon Khen in Thailand, vol. 6; 2006. p. 40-8.

41. Risal A, Manandhar K, Linde M, Steiner TJ. Holen A. Anxiety and depression in Nepal: prevalence, comorbidity and associations. BMC psychiatry. 2016;16:102.

42. Acharya B, Hirachan S, Mandel JS, van Dyke C. The Mental Health Education Gap among Primary Care Providers in Rural Nepal. Acad Psychiatry. 2016;40(4):667-71.
43. Demyttenaere K, Bruffaerts R, Posada-Villa J, Gasquet I, Kovess V, Lepine JP, Angermeyer MC, Bernert S, de Girolamo G, Morosini P, et al. Prevalence, severity, and unmet need for treatment of mental disorders in the World Health Organization World Mental Health Surveys. JAMA. 2004;291(21):2581-90.

44. Ahmedani BK, Kubiak SP, Kessler RC, de Graaf R, Alonso J, Bruffaerts R, Zarkov Z, Viana MC, Huang YQ, Hu C, et al. Embarrassment when illness strikes a close relative a World Mental Health Survey Consortium Multi-Site Study. Psychol Med. 2013;43(10):2191-202.

45. Skapinakis $P$, Weich $S$, Lewis $G$, Singleton N, Araya R. Socio-economic position and common mental disorders. Longitudinal study in the general population in the UK. Br J Psychiatry. 2006;189:109-17.

46. Leung KK, Chen CY, Lue BH, Hsu ST. Social support and family functioning on psychological symptoms in elderly Chinese. Arch Gerontol Geriatr. 2007; 44(2):203-13.

47. Wang J, Zhao X. Family functioning and social support for older patients with depression in an urban area of Shanghai, China. Arch Gerontol Geriatr. 2012;55(3):574-9.

48. Gong Y, Wen X, Guan C, Wang Z, Liang Y. The associations between family characteristics and depressive symptoms in older adults a community-based survey in rural China. Int Psychogeriatr. 2012;24(8):1226-34.

49. Acharya P. The Situation of Population Ageing and Social Security for Elderly People in Nepal. Health Prospect. 2018;10:61-3. https://doi.org/10.3126/ hprospect.v10i0.5658.

50. Sandhya Gl. Geriatric Depression and Related Factors -A Cross sectional Study From a Rural Community in South Kerala. J Ind Acad Geriatr. 2010;6: 61-3.

51. Nicolosi GT, Falcao DV, Batistoni SS, Lopes A, Cachioni M, Neri AL, Yassuda MS. Depressive symptoms in old age relations among sociodemographic and self-reported health variables. Int Psychogeriatr. 2011;23(6):941-9.

\section{Publisher's Note}

Springer Nature remains neutral with regard to jurisdictional claims in published maps and institutional affiliations.

Ready to submit your research? Choose BMC and benefit from:

- fast, convenient online submission

- thorough peer review by experienced researchers in your field

- rapid publication on acceptance

- support for research data, including large and complex data types

- gold Open Access which fosters wider collaboration and increased citations

- maximum visibility for your research: over $100 \mathrm{M}$ website views per year

At $\mathrm{BMC}$, research is always in progress.

Learn more biomedcentral.com/submissions 